\title{
Euglycemic state reduces the incidence of critical illness polyneuropathy and duration of ventilator dependency in medical intensive care unit
}

\author{
Mikaeili $\mathrm{H}^{1}$, Yazdchi $\mathrm{M}^{2}$, Barazandeh $\mathrm{F}^{3}$, Ansarin $\mathrm{K}^{1}$ \\ Tuberculosis and Lung Disease Research Center, Tabriz University of Medical Sciences, Tabriz, Iran. \\ yazdchim@yahoo.com
}

\begin{abstract}
Objective: To examine the effect of euglycemic blood glucose control with normal insulin therapy on the incidence of critical illness polyneuropathy and duration of mechanical ventilation compared to that of conventional insulin therapy in a medical ICU.

Background: Despite the criticism over increased risk of hypoglycemia, the prevention of hyperglycemia through intensive insulin therapy has recently been confirmed to reduce the critical illness polyneuropathy (CIP).

Methods: In a single blind randomized clinical trial, forty adult patients admitted to the medical ICU were randomized to either euglycemic control $(80-140 \mathrm{mg} / \mathrm{dL})$ (Group N) or conventional approach (180-200 mg/dL, Group C). Duration of mechanical ventilation and the presence of CIP were investigated.

Results: The mean blood glucose levels were $131.76 \pm 40.15 \mathrm{mg} / \mathrm{dL}$ in group $\mathrm{N}$ and $169.87 \pm 50.66 \mathrm{mg} / \mathrm{dL}$ in group $C(p<0.001)$. Patients in group $N$ were on mechanical ventilation for significantly less time than those in group $C(p=0.04)$. The diagnosis of CIP was significantly more frequent in group $C$ than in group $N(p=0.01)$. Conclusions: Glucose control at levels $80-140 \mathrm{mg} / \mathrm{dL}$ with normal insulin administration is likely to be associated with both reduced incidence of CIP and duration of ventilator dependency in medical ICU (Tab. 3, Ref. 24). Full Text in PDF www.elis.sk.

Key words: blood glucose, insulin, euglycemic, critical illness polyneuropathy, ventilator, intensive care unit.
\end{abstract}

Critical illness polyneuropathy (CIP) principally affects the motor and sensory axons in critically ill patients $(1,2)$. This disorder not only causes severe limb weakness and subsequent prolonged rehabilitation but also detrimentally protracts weaning from mechanical ventilation $(1,3)$. The latter is attributed to the involvement of the phrenic nerves and the diaphragm, intercostal and other accessory respiratory muscles (4). Numerous related risk factors have been studied among which sepsis, systemic inflammatory response syndrome, and multiple organ failure have been recognized as fundamental parameters (5). Also, the role of corticosteroids and neuromuscular blocking agents in the development of CIP is still a matter of controversy (1). Recognition of these risk factors is of the utmost importance since only preventive and supportive measures have hitherto been recommended to hinder the progression of CIP (1). Nevertheless, among these probable interventions, only prevention of hyperglycemia through

${ }^{1}$ Tuberculosis and Lung Disease Research Center, Tabriz University of Medical Sciences, Tabriz, Iran, ${ }^{2}$ Neurosciences Research Center, Tabriz University of Medical Sciences, Tabriz, Iran, and ${ }^{3}$ Department of Internal Medicine, Tabriz University of Medical Sciences, Tabriz, Iran

Address for correspondence: M. Yazdchi, MD, Neurosciences Research Center, Tabriz University of Medical Sciences, Tabriz, Iran.

Phone/Fax: +984113342889

Acknowledgement: This study was financially supported by a grant from Tuberculosis and Lung Disease Research Center, Tabriz University of Medical Sciences, Iran. intensive insulin therapy (IIT) has recently been confirmed to benefit patients admitted to the intensive care unit (ICU) $(1,6)$. In the Leuven trials, Van den Berghe et al. found that tight blood glucose control with insulin in medical/surgical ICU reduced CIP and the need for prolonged mechanical ventilation (7-9). Nonetheless, blood glucose at the target level of $80-110 \mathrm{mg} / \mathrm{dL}$ has been criticized because it increases the risk of hypoglycemia and subsequent mortality (10). Therefore, our aim was to examine the effect of euglycemia (aiming at a blood glucose level of 80-140 $\mathrm{mg} / \mathrm{dL}$ ) through normal insulin therapy (NIT) on the incidence of CIP and duration of mechanical ventilation compared to that of conventional insulin therapy in a medical ICU population.

\section{Methods}

In a single blind randomized clinical trial during eighteen months from July 2005 to January 2007, forty adult patients (2080 years) admitted to the university-affiliated medical ICU with Acute Physiology and Chronic Health Evaluation (APACHE II) with score $>10$ were eligible for inclusion. The study was approved by the local ethics committee and written informed consent was obtained from the closest family member. Exclusion criteria were (1) history of diabetes mellitus (blood glucose level $\geq 126 \mathrm{mg} / \mathrm{dL}$ ) with or without medical therapy, (2) history of cirrhosis or chronic liver disease, (3) history of malignancy, (4) body mass index $(\mathrm{BMI})<8$ or $>35,(5)$ a 48 -hour delay in admission to ICU, and 
(6) diagnosis of polyneuropathy on second-day electrophysiological study (see Electrophysiological study). Of forty patients, 20 cases were randomized to euglycemic control with normal insulin therapy $($ Group $\mathrm{N})$ and the remaining to the conventional approach (Group C). Age, gender, height, weight, BMI, APACHE II score, blood glucose level, values of electrodiagnostic study in upper and lower limbs, duration of mechanical ventilation, and presence of CIP were recorded. The blood glucose level was measured on admission and daily at 6 A.M. Laboratory personnel were unaware of the treatment assignments. The feeding regimen and medical interventions were similar in both groups.

\section{Blood glucose measurements}

With the aim of maintaining blood glucose level in the range of 80-140 mg/dL in the normal insulin therapy group (Group N), insulin infusion was started when a glucose level over $140 \mathrm{mg} / \mathrm{dL}$ was detected. Once the blood glucose level fell below $100 \mathrm{mg} / \mathrm{dL}$, blood glucose level measurements were performed every hour. At a glucose level of $60 \mathrm{mg} / \mathrm{dL}$, insulin infusion was stopped. With diagnosis of hypoglycemia at blood glucose levels below $45 \mathrm{mg}$ / $\mathrm{dL}$, intravenous glucose (50\%) was given. Infusion of insulin was not started until the blood glucose rose above $140 \mathrm{mg} / \mathrm{dL}$. The conventional insulin therapy (Group C) approach required insulin only when the blood glucose rose above $250 \mathrm{mg} / \mathrm{dL}$. The insulin dose was regulated on the basis of blood glucose levels measured at one-to-four hour intervals in capillary blood. Conventional insulin therapy was aimed at blood glucose levels between 180 and 200 $\mathrm{mg} / \mathrm{dL}$, i.e. infusion of insulin was stopped when blood glucose fell below $180 \mathrm{mg} / \mathrm{dL}$. In both groups, the infusion of insulin was discontinued when enteral feeding was halted.

\section{Electrophysiological study}

All the recruited patients were assessed electrophysiologically on days 2, 10 and 18 after admission. Patients with pre-existing neuromuscular disorders due to diabetes mellitus, chronic renal failure, cirrhosis and malignancies were excluded. In addition, patients whose second-day electrophysiological study was suggestive of polyneuropathy were not included. Electrodiagnostic surveys were performed by an independent neurologist (M.Y.M) who was unaware of treatment allocation. Sensory and motor nerve conduction velocities (NCV) and amplitude of action potentials were recorded by an EMG-NC (Toenniss Neuroscreen plus, Erich
Jaeger GmbH, Hoechberg, Germany). Compound muscle action potential (CMAP) was assessed by stimulation of the median, ulnar, peroneal and tibial nerves and on abductor pollicis brevis, abductor digiti minimi, extensor digitorum brevis, and abductor hallucis muscles. Sensory nerve action potential (SNAP) values on the sural nerve and sensory parts of the median and ulnar nerves were also recorded. The diagnosis of critical illness polyneuropathy (CIP) was based on a reduction of $>10 \%$ in the values of CMAP and SNAP and confirmed by physical examination of the patient.

\section{Weaning strategies}

Mechanically ventilated patients were evaluated daily for the probability of weaning based on improvement in indicators for mechanical ventilation, cardiovascular status, arterial blood gas parameters, ventilator settings and neurological status. If these criteria were met, a weaning-trial was performed using spontaneous breathing trials of at least 30 and up to 120 minutes. If the spontaneous breathing trial was successful, based on subjective tolerance, respiratory and hemodynamic parameters, the patients were extubated.

\section{Statistics}

Data are presented as mean \pm standard deviation (SD). Statistical analysis was performed using SPSS for Windows version 13.0 (Chicago, IL) using Chi-square test, Fisher's exact test, MannWhitney U test, and Independent-Samples $t$ test wherever appropriate. A $p$ value $<0.05$ was considered statistically significant.

\section{Results}

A total of 40 of the 313 patients admitted to the medical ICU were evaluated; 20 patients in group $\mathrm{N}$ and 20 cases in group $\mathrm{C}$. Demographic baseline data and outcome characteristics of these patients are shown in Table 1. There were no differences in gender, age, BMI and APACHE II score (Tab. 1) ( $p>0.05)$. The mean APACHE II score of all patients in both groups studied was 16.08 \pm 3.47 (range: $11-24$ ). According to the above definition, hypoglycemia was detected in five patients on blood glucose level measurements with a glucometer $(p>0.05)$. None of these instances was accompanied by adverse events including cardiac arrest, seizures, and hypoglycemia-induced coma. The mean blood glucose levels (6 A.M.) were $131.76 \pm 40.15 \mathrm{mg} / \mathrm{dL}$ in group $\mathrm{N}$ and $169.87 \pm 50.66 \mathrm{mg} / \mathrm{dL}$ in group $\mathrm{C}(\mathrm{p}<0.001$, Mann-Whitney $\mathrm{U}$

Tab. 1. Demographic and outcome characteristics of study patients.

\begin{tabular}{|c|c|c|c|}
\hline & Group N $(n=20)$ & Group C $(\mathrm{n}=20)$ & $\mathrm{p}$ value \\
\hline Gender (male:female) & $9: 11$ & $8: 12$ & 0.74 \\
\hline Age (years) & $52.65 \pm 18.63$ & $52.35 \pm 18.46$ & 0.95 \\
\hline BMI (kg/m2) & $26.20 \pm 4.47$ & $28.01 \pm 5.13$ & 0.24 \\
\hline Baseline APACHE II score & $16.15 \pm 3.21$ & $16.00 \pm 3.79$ & 0.89 \\
\hline Blood glucose level (mg/dL) & $131.76 \pm 40.15$ & $169.87 \pm 50.66$ & $<0.001 *$ \\
\hline Sepsis: $\mathrm{n}(\%)$ & $4(20)$ & $5(25)$ & 1.00 \\
\hline Multiple organ failure: n (\%) & $4(20)$ & $3(15)$ & 1.00 \\
\hline Days on ventilator & $9.72 \pm 3.84$ & $14.05 \pm 8.14$ & $0.04 *$ \\
\hline Critical illness polyneuropathy: n (\%) & $2(10)$ & $9(45)$ & $0.01 *$ \\
\hline
\end{tabular}

Group N - normal insulin therapy group; Group C - conventional insulin therapy group; BMI - body mass index; APACHE II - Acute Physiology and Chronic Health Evaluation II score. " statistically significant. 
Tab. 2. Electrophysiological data of the upper limbs.

\begin{tabular}{|c|c|c|c|c|c|c|c|c|c|}
\hline & \multicolumn{3}{|c|}{ At day 10} & \multicolumn{3}{|c|}{ At day 18} & \multicolumn{3}{|c|}{ Difference } \\
\hline & Group N & Group C & $\mathrm{p}$ value & Group N & Group C & $\mathrm{p}$ value & Group N & Group C & $\mathrm{p}$ value \\
\hline Sensory amplitude (mV) & $28.38 \pm 14.85$ & $24.23 \pm 10.32$ & 0.31 & $29.38 \pm 16.34$ & $26.46 \pm 12.48$ & 0.53 & $0.99 \pm 3.60$ & $2.23 \pm 6.95$ & 0.48 \\
\hline Motor amplitude (mV) & $6.34 \pm 3.18$ & $7.03 \pm 3.46$ & 0.52 & $6.54 \pm 3.28$ & $6.06 \pm 3.00$ & 0.63 & $0.19 \pm 1.67$ & $-0.96 \pm 3.27$ & 0.16 \\
\hline Sensory NCV (ms) & $50.64 \pm 5.34$ & $49.08 \pm 3.68$ & 0.29 & $46.98 \pm 8.14$ & $44.89 \pm 4.53$ & $0.02 *$ & $-3.66 \pm 9.37$ & $-4.19 \pm 6.16$ & 0.83 \\
\hline Motor NCV (ms) & $54.35 \pm 7.54$ & $56.46 \pm 7.21$ & 0.37 & $56.00 \pm 6.79$ & $51.35 \pm 8.10$ & $0.05^{*}$ & $1.65 \pm 7.31$ & $-5.11 \pm 7.79$ & $0.007 *$ \\
\hline
\end{tabular}

Group N - normal insulin therapy group; Group C - conventional insulin therapy group; NCV - nerve conduction velocity; " statistically significant.

Tab. 3. Electrophysiological data of the lower limbs.

\begin{tabular}{|c|c|c|c|c|c|c|c|c|c|}
\hline & \multicolumn{3}{|c|}{ At day 10} & \multicolumn{3}{|c|}{ At day 18} & \multicolumn{3}{|c|}{ Difference } \\
\hline & Group N & Group C & $\mathrm{p}$ value & Group N & Group C & $\mathrm{p}$ value & Group N & Group C & $\mathrm{p}$ value \\
\hline Sensory amplitude (mV) & $16.05 \pm 8.61$ & $12.19 \pm 7.35$ & 0.13 & $15.90 \pm 8.21$ & $9.48 \pm 8.88$ & $0.02 *$ & $-0.15 \pm 4.71$ & $-2.71 \pm 6.55$ & 0.16 \\
\hline Motor amplitude (mV) & $4.36 \pm 2.74$ & $3.82 \pm 1.96$ & 0.49 & $3.52 \pm 2.93$ & $2.22 \pm 1.01$ & 0.07 & $-0.84 \pm 1.64$ & $-1.59 \pm 1.53$ & 0.14 \\
\hline Sensory NCV (ms) & $51.08 \pm 7.74$ & $53.03 \pm 7.79$ & 0.43 & $50.49 \pm 8.78$ & $36.96 \pm 17.19$ & $0.003^{*}$ & $-0.58 \pm 12.62$ & $-16.06 \pm 20.64$ & $0.007^{*}$ \\
\hline Motor NCV (ms) & $47.25 \pm 5.46$ & $41.20 \pm 7.00$ & $0.005 *$ & $44.18 \pm 8.37$ & $40.00 \pm 8.95$ & 0.14 & $-3.07 \pm 7.45$ & $-1.22 \pm 8.73$ & 0.48 \\
\hline
\end{tabular}

Group $\mathrm{N}$ - normal insulin therapy group; Group $\mathrm{C}$ - conventional insulin therapy group; NCV - nerve conduction velocity; * statistically significant.

test) (Tab. 1). Patients in group $\mathrm{N}$ were on mechanical ventilator for significantly less time than those in group C (9.72 \pm 3.84 vs. $14.05 \pm 8.14$ days, $\mathrm{p}=0.04$, Mann-Whitney $U$ test).

An electrophysiologically based diagnosis of CIP was significantly more frequent in group $\mathrm{C}(9 / 20(45 \%))$ than in group $\mathrm{N}$ $(2 / 20(10 \%))(p=0.01$, Fisher's exact test $)$. Features of limb nerve conduction on days 10 and 18 are listed in Tables 2 and 3. The electrodiagnostic survey on day 18 showed that the mean sensory NCV of upper limbs in group C ( $44.89 \pm 4.53 \mathrm{~ms})$ was significantly lower than that in group $\mathrm{N}(46.98 \pm 8.14 \mathrm{~ms})(\mathrm{p}=0.02)($ Tab. 2$)$. Furthermore, after one week, patients in group $\mathrm{C}$ showed greater reduction in motor NCV (upper limbs) and sensory NCV (lower limbs) than patients in group $\mathrm{N}(\mathrm{p}=0.007)$ (Tabs 2 and 3$)$. In the lower limbs, electrophysiological values of the sensory nerves (amplitude and sensory NCV at day 18) were significantly higher in group $\mathrm{N}(\mathrm{p}<0.05)$ (Tab. 3).

\section{Discussion}

The present study showed that in comparison to the conventional control of blood glucose, NIT may reduce the incidence of CIP and duration of ventilator dependency in the medical ICU. The results of this study complement those of previous publications. In a study on patients in surgical ICU, Van den Berghe et al. found that strict control of blood glucose levels by insulin (aimed at maintaining glycemia of $80-110 \mathrm{mg} / \mathrm{dL}$ ) reduced CIP and the need for prolonged mechanical ventilation $(7,8)$. Later in Leuven, Van den Berghe and colleagues studied the same insulin titration protocol in medical ICU. They obtained findings similar to those of the previous surgical ICU investigation, revealing a reduced incidence of CIP and earlier weaning from mechanical ventilation in patients on IIT $(2,9)$. These conclusions have recently been reconfirmed in an electrophysiologically based retrospective study in the medical/surgical ICU (5). In the present study, patients with history of diabetes mellitus were excluded in order to investigate the effects of normal glucose control on stress-induced hyperglycemia $(\mathrm{SIH})$ rather than on diabetic hyperglycemia. We believe that this is an important characteristic of our study. Although increased risk of hospital mortality and longer duration of hospitalization have been indicated in SIH vs. diabetic hyperglycemia, most of the recent randomized studies have included both SIH and diabetic hyperglycemia in the same analysis (10).

Diagnosis of CIP is based on technical investigations including measurements of serum creatine kinase, electrophysiological studies, and muscle biopsy (10). Among these, electrophysiological studies (EMG/NCV) are applied not only to confirm the diagnosis but also to rule out other neuromuscular causes of weakness $(1,10)$. Prior to the onset of clinical symptoms and electromyographical changes there is a reduction in amplitude of CMAP and/or SNAP with preserved conduction velocity $(1,11)$. However, some believe that a decline in SNAP amplitude occurs later than in CMAP (3, 10). Although in most previous studies examining the role of IIT in CIP, CIP has been diagnosed according to the above criteria (2, 7-9), they have almost all neglected to report their electrophysiological data. Nonetheless, Hermans and coworkers reported that SNAP values in the upper limbs were significantly increased in their IIT group (5). They attributed the absence of electrophysiological alterations in the lower limbs to the vulnerability of the sural nerve to tissue edema (5).

The core mechanism underlying the beneficial effects of IIT in reducing mortality and morbidity might be partially elucidated by a hypothesis of impaired microvascular circulation $(11,13)$. According to this hypothesis, hyperglycemia in critically ill patients may lead to impairment of microcirculation to peripheral nerves, augmenting the occurrence of CIP $(11,13)$. Later studies of IIT concerning asymmetric dimethylarginine (nitric oxide synthase inhibitor) (14), intracellular adhesion molecules and E-selectin (15) seem consistent with the hypothesis. Moreover, the plausible anti-inflammatory effects of insulin (16) and its protective effects on neuronal mitochondria $(8,17)$ and serum lipid profile $(18)$ have been linked to reduced incidence of CIP in patients on IIT. Nevertheless, tight glucose control (aimed at maintaining glycemia of $80-110 \mathrm{mg} / \mathrm{dL}$ ) has often been accompanied by increased risk of hypoglycemia $(7,9,19)$. For that reason, two recent related trials have been stopped $(20,21)$. Apart from the hypoglycemia-related criticisms of IIT, Fahy et al. reviewed recent studies that failed to 
reveal significant differences between IIT and conventional therapy groups regarding morbidity and mortality (10). Likewise, the findings of the Normoglycemia in Intensive Care Evaluation and Survival Using Glucose Algorithm Regulation (NICE-SUGAR) study revealed greater mortality and more severe hypoglycemia in IIT than in conventional therapy groups $(22,23)$. On the basis of these results, the American Diabetes Association and the American Association of Clinical Endocrinologists have recommended that until more data are available, it is reasonable to treat critically ill patients less rigorously rather than attempt to achieve blood glucose levels in the range of 80 to $108 \mathrm{mg} / \mathrm{dL}$ (24). At the target blood glucose level of $80-140 \mathrm{mg} / \mathrm{dL}$, patients on NIT in the present study developed fewer CIPs and remained for shorter times on mechanical ventilation than those on conventional therapy. Moreover, a similar incidence of hypoglycemia with no subsequent adverse complications between the two groups in our study further highlights the benefits of NIT compared to tight glucose control through IIT.

In conclusion, control of glucose levels at $80-140 \mathrm{mg} / \mathrm{dL}$ with normal insulin administration is likely to be associated with both reduced incidence of CIP and duration of ventilator dependency in medical ICU. Further investigations are needed to assess the benefits of blood glucose control at different targets, in particular those less aggressively achieved by insulin administration.

\section{References}

1. Hermans G, De Jonghe B, Bruyninckx F, Van den Berghe G. Clinical review: critical illness polyneuropathy and myopathy. Crit Care 2008; 12: 238.

2. Hermans G, Wilmer A, Meersseman W, Milants I, Wouters PJ, Bobbaers H, Bruyninckx F, Van den Berghe G. Impact of intensive insulin therapy on neuromuscular complications and ventilator dependency in the medical intensive care unit. Am J Respir Crit Care Med 2007; 175: 480-489.

3. Zifko UA, Zipko HT, Bolton CF. Clinical and electrophysiological findings in critical illness polyneuropathy. J Neurol Sci 1998; 159: 186-193.

4. Dhand UK. Clinical approach to the weak patient in the intensive care unit. Resp Care 2006; 51: 1024-1040.

5. Hermans G, Schrooten M, Van Damme P, Berends N, Bouckaert B, De Vooght W, Robberecht W, Van den Berghe G. Benefits of intensive insulin therapy on neuromuscular complications in routine daily critical care practice: a retrospective study. Crit Care 2009; 13: R5.

6. Hermans G, De Jonghe B, Bruyninckx F, Van den Berghe G. Interventions for preventing critical illness polyneuropathy and critical illness myopathy. Cochrane Database Syst Rev 2009; (1): CD006832.

7. van den Berghe G, Wouters P, Weekers F, Verwaest C, Bruyninckx F, Schetz M, Vlasselaers D, Ferdinande P, Lauwers P, Bouillon R. Intensive insulin therapy in critically ill patients. N Engl J Med 2001; 345: 1359-1367.

8. Van den Berghe G, Schoonheydt K, Becx P, Bruyninckx F, Wouters PJ. Insulin therapy protects the central and peripheral nervous system of intensive care patients. Neurology 2005; 64: 1348-1353.

9. Van den Berghe G, Wilmer A, Hermans G, Meersseman W, Wouters PJ, Milants I, Van Wijngaerden E, Bobbaers H, Bouillon R. Intensive insulin therapy in the medical ICU. N Engl J Med 2006; 354: 449-461.

10. Fahy BG, Sheehy AM, Coursin DB. Glucose control in the intensive care unit. Crit Care Med 2009; 37: 1769-1776.
11. Bolton CF. Neuromuscular manifestations of critical illness. Muscle Nerve. 2005; 32: 140-163.

12. Maramattom BV, Wijdicks EF. Acute neuromuscular weakness in the intensive care unit. Crit Care Med 2006; 34: 2835-2841.

13. Hermans G, Vanhorebeek I, Derde S, Van den Berghe G. Metabolic aspects of critical illness polyneuromyopathy. Crit Care Med 2009; 37: S391-S397.

14. Siroen MP, van Leeuwen PA, Nijveldt RJ, Teerlink T, Wouters PJ, Van den Berghe G. Modulation of asymmetric dimethylarginine in critically ill patients receiving intensive insulin treatment: A possible explanation of reduced morbidity and mortality? Crit Care Med 2005; 33: 504-510.

15. Langouche L, Vanhorebeek I, Vlasselaers D, Vander Perre S, Wouters PJ, Skogstrand K, Hansen TK, Van den Berghe G. Intensive insulin therapy protects the endothelium of critically ill patients. J Clin Invest 2005; 115 : 2277-2286.

16. Hansen TK, Thiel S, Wouters PJ, Christiansen JS, Van den Berghe G. Intensive insulin therapy exerts antiinflammatory effects in critically ill patients and counteracts the adverse effect of low mannose-binding lectin levels. J Clin Endocrinol Metab 2003; 88: 1082-1088.

17. Vanhorebeek I, De Vos R, Mesotten D, Wouters PJ, De Wolf-Peeters C, Van den Berghe G. Protection of hepatocyte mitochondrial ultrastructure and function by strict blood glucose control with insulin in critically ill patients. Lancet 2005; 365: 53-59.

18. Mesotten D, Swinnen JV, Vanderhoydonc F, Wouters PJ, Van den Berghe G. Contribution of circulating lipids to the improved outcome of critical illness by glycemic control with intensive insulin therapy. J Clin Endocrinol Metab 2004; 89: 219-226.

19. Van den Berghe G, Wouters PJ, Bouillon R, Weekers F, Verwaest C, Schetz M, Vlasselaers D, Ferdinande P, Lauwers P. Outcome benefit of intensive insulin therapy in the critically ill: Insulin dose versus glycemic control. Crit Care Med 2003; 31: 359-366.

20. Brunkhorst FM, Engel C, Bloos F, Meier-Hellmann A, Ragaller M, Weiler N, Moerer O, Gruendling M, Oppert M, Grond S, Olthoff D, Jaschinski U, John S, Rossaint R, Welte T, Schaefer M, Kern P, Kuhnt E, Kiehntopf M, Hartog C, Natanson C, Loeffler M, Reinhart K; German Competence Network Sepsis (SepNet). Intensive insulin therapy and pentastarch resuscitation in severe sepsis. N Engl J Med 2008; 358: 125-139.

21. Devos P, Preiser JC. Current controversies around tight glucose control in critically ill patients. Curr Opin Clin Nutr Metab Care 2007; 10: 206-209.

22. Gibson BR, Galiatsatos P, Rabiee A, Eaton L, Abu-Hamdah R, Christmas C, Milner SM, Andersen DK, Elahi D. Intensive insulin therapy confers a similar survival benefit in the burn intensive care unit to the surgical intensive care unit. Surgery 2009; 146: 922-930.

23. NICE-SUGAR Study Investigators, Finfer S, Chittock DR, Su SY, Blair D, Foster D, Dhingra V, Bellomo R, Cook D, Dodek P, Henderson WR, Hébert PC, Heritier S, Heyland DK, McArthur C, McDonald E, Mitchell I, Myburgh JA, Norton R, Potter J, Robinson BG, Ronco JJ. Intensive versus conventional glucose control in critically ill patients. N Engl J Med 2009; 360: 1283-1297.

24. American Association of Clinical Endocrinologists. Joint Statement from the American Diabetes Association and American Association of Clinical Endocrinologists on the NICE-SUGAR Study on intensive versus conventional glucose control in critically ill patients. Available from: http:// media.aace.com/article_display.cfm?article_id=4886. Published March 24, 2009. Accessed April 4, 2010.

Received December 20, 2010. Accepted June 26, 2012. 